\title{
COLGAJO DE ANTIA-BUCH PARA RECONSTRUCCIÓN DE DEFECTOS DEL BORDE HELICIAL. DESCRIPCIÓN DE UN CASO
}

\author{
Antia-Buch flap reconstruction for helical rim defects. Case report \\ Carmen SALOM-COVEÑAS; Matilde HARO-GARCÍA; Eulalia PORRAS ALONSO \\ Hospital Universitario de Puerto Real. Servicio de Otorrinolaringología. Puerto Real. Cádiz. España. \\ Correspondencia:carmen_salom@hotmail.com
}

Fecha de recepción: 13 de abril de 2019

Fecha de aceptación: 12 de mayo de 2019

Fecha de publicación: 13 de mayo de 2019

Fecha de publicación del fascículo: 1 de diciembre de 2019

Conflicto de intereses: Los autores declaran no tener conflictos de intereses

Imágenes: Los autores declaran haber obtenido las imágenes con el permiso de los pacientes Política de derechos y autoarchivo: se permite el autoarchivo de la versión post-print (SHERPA/RoMEO)

Licencia CC BY-NC-ND. Licencia Creative Commons Atribución-NoComercial-SinDerivar 4.0 Internacional Universidad de Salamanca. Su comercialización está sujeta al permiso del editor

RESUMEN: Introducción y objetivo: El colgajo Antia-Buch es un procedimiento en el que se utilizan dos colgajos condrocutáneos para reconstruir la región helicial del pabellón auricular. La laxitud del tejido se confiere, en gran medida, por el colgajo inferior y se requiere la resección condrocutánea de la escafa para el cierre. Esto da como resultado la pérdida de la altura de la oreja. Nuestro objetivo es realizar la exéresis de una lesión de mediano tamaño sin comprometer la morfología del pabellón auricular. Descripción: Realizamos una reconstrucción por colgajo de Antia-Buch en paciente con carcinoma espinocelular de hélix derecho. Resultados: Se extirpa carcinoma epidermode con márgenes libres obteniendo un buen resultado estético del pabellón auricular. Discusión: El colgajo de Antia-Buch es utilizado para defectos de mediano tamaño de la región helicial. Entre los distintos pasos quirúrgicos hay que destacar las descargas V-Y para evitar tensión en los tejidos y conservar el pericondrio del colgajo para la nutrición condral. Conclusiones: Técnica en la que se obtiene buen resultado estético, sin comprometer la radicalidad de la excisión.

Palabras clave: tumor hélix; colgajo Antia-Buch; reconstrucción hélix. 


\title{
COLGAJO DE ANTIA-BUCH PARA RECONSTRUCCIÓN DE DEFECTOS DEL BORDE HELICIAL. DESCRIPCIÓN DE UN CASO \\ SALOM-COVEÑAS C ET AL
}

\begin{abstract}
SUMMARY: Introduction and objective: The Antia-Buch flap is a procedure in which two chondrocutaneous flaps are used to reconstruct the helicial region of the auricular pinna. The laxity of the tissue is conferred, to a large extent, by the inferior flap and the chondrocutaneous resection of the scafa is required for closure. This results in the loss of the height of the ear. Our objective is to perform the exeresis of a medium-sized lesion without compromising the morphology of the auricular pinna. Description: We performed an Antia-Buch flap reconstruction in a patient with spinocellular carcinoma of the right helix. Results: Squamous cell carcinoma with free margins was removed obtaining a good aesthetic result of the auricular pinna. Discussion: The Antia-Buch flap is used for medium size defects of the helicial region. Among the different surgical steps, highlight the V-Y discharges to avoid tension in the tissues and conserve the perichondrium of the flap for chondral nutrition. Conclusions: Technique in which good aesthetic results are obtained, without compromising the radicality of the excision.
\end{abstract}

Keywords: helix tumor; Antia-Buch flap; helix reconstruction.

\section{INTRODUCCIÓN}

El carcinoma espinocelular es una de las neoplasia cutáneas más frecuente; con predominio de localización en áreas foto-expuestas, como el pabellón auricular. El tratamiento de elección es quirúrgico, consiguiendo una resección completa con márgenes adecuados. Por otra parte, los resultados estéticos y funcionales son importantes [1]. La anatomía del pabellón auricular presenta numerosos pliegues, surcos y ondulaciones, una estructura compuesta de piel sobre cartílago y un soporte vasculonervioso distribuido por ambas superficies cutánea y pericondrial, siendo especialmente rico en el lóbulo auricular. El cartílago auricular ocupa los dos tercios superiores de la oreja y es avascular, por lo que recibe sus nutrientes del pericondrio adyacente. La irrigación del pabellón auricular deriva de la arteria temporal superficial y la auricular posterior; ambas provenientes de la carótida externa. La presencia de varias anastomosis vasculares, que conectan la rama superior e inferior de la arteria temporal superficial, permite la utilización de una amplia variedad de colgajos [2].

\section{DESCRIPCIÓN}

Varón de 84 años con carcinoma espinocelular en tercio medio de hélix del pabellón auricular
(Figura 1) que presentó un rápido crecimiento en los últimos 2 meses; sin otros antecedentes de interés. Se trataba de un tumo exofítico de 31 $\mathrm{mm}$ (Figura 2) que necesitó una resección con suficientes márgenes $(1 \mathrm{~cm})$, para asegurar una extirpación completa. En el mismo tiempo se realizó una reconstrucción, utilizando el colgajo de Antia-Buch. Se diseñó el colgajo (Figura 3) y se realizó una incisión en la piel y el cartílago en surco helicial con una pequeña descarga en $\mathrm{V}$ a nivel de la raíz helicial para evitar mayor tensión de tejidos en el cierre (Figura 4). Disección de la piel hasta el surco retroauricular, respetando pericondrio y cartílago auricular (Figura 5); por encima de músculo auricular posterior. Se realizó triángulo compensatorio de Burow en la región posterior del defecto para lograr un mejor cierre sin perder la orientación del pabellón. Se resecó parte del cartílago de la escafa para evitar mayor tensión en la reaproximación de los bordes. Se suturó con seda de 4.0 con punto colchonero y punto simple, apreciando una reducción de la circunferencia total del oído y de la altura vertical, aunque con resultados morfológicos satisfactorios (Figura 6). El posoperatorio cursó sin incidencias. La forma del pabellón auricular fue restaurada satisfactoriamente (Figura 7). El estudio anatomopatológico reveló que la lesión extirpada era un carcinoma epidermoide con márgenes libres. 


\section{COLGAJO DE ANTIA-BUCH PARA RECONSTRUCCIÓN DE DEFECTOS DEL BORDE HELICIAL. DESCRIPCIÓN DE UN CASO \\ SALOM-COVEÑAS C ET AL}

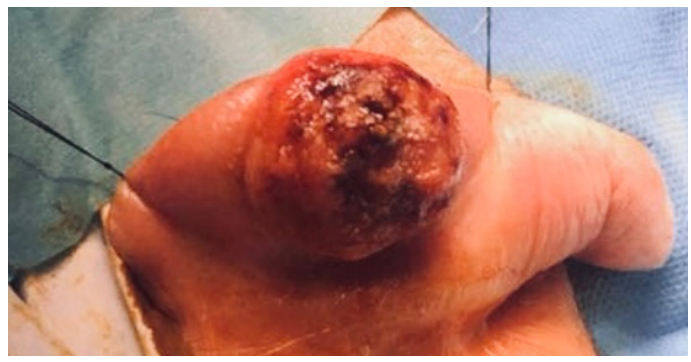

Figura1. Tumoración en tercio medio del hélix.

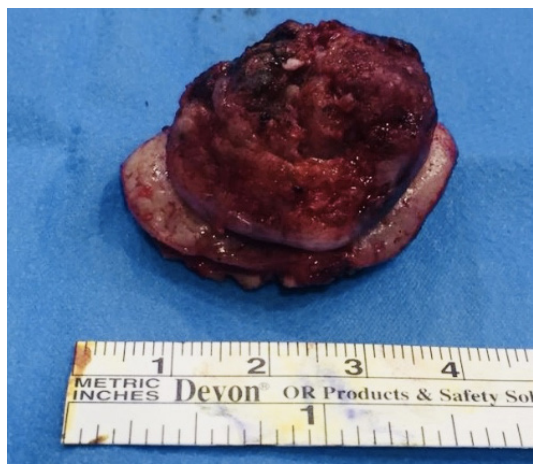

Figura 2. Carcinoma espinocelular de $31 \mathrm{~mm}$.

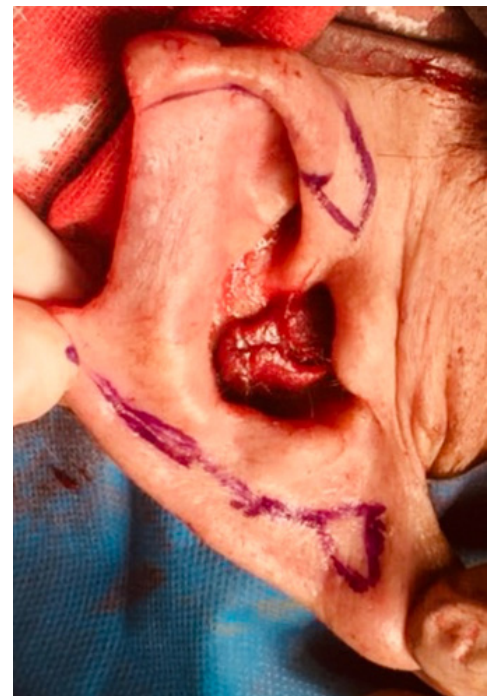

Figura 3. Diseño del colgajo de Antia-Buch.

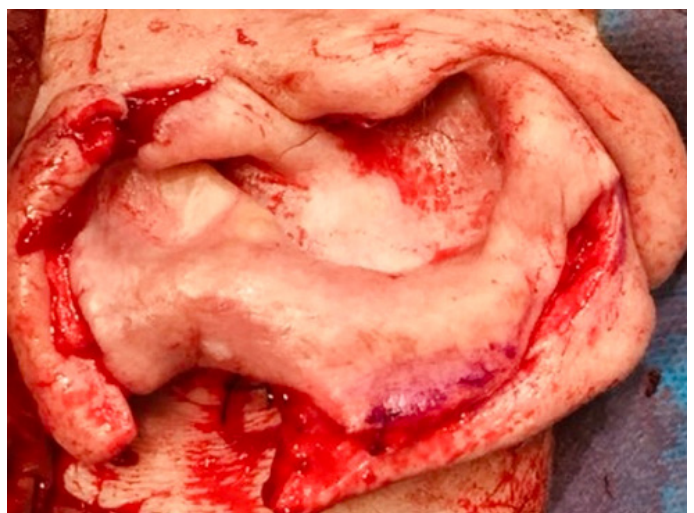

Figura 4: Incisión y despegamiento de colgajo.

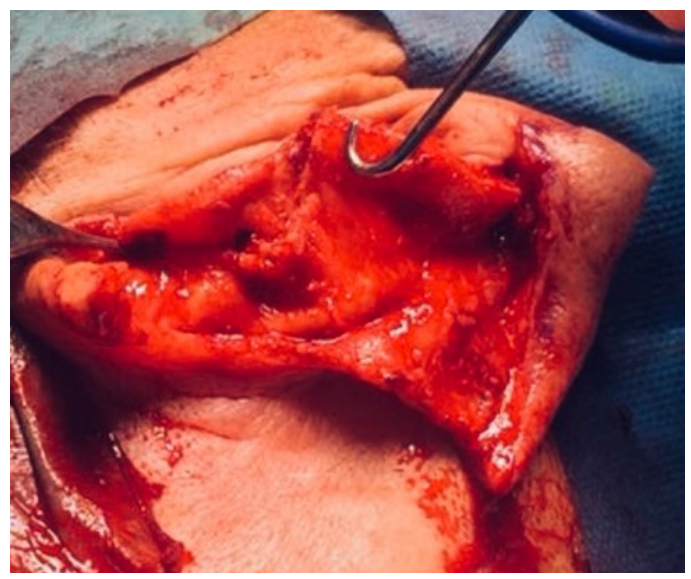

Figura 5. Despegamiento de colgajo hasta surco retroauricular con triángulo de Burow.

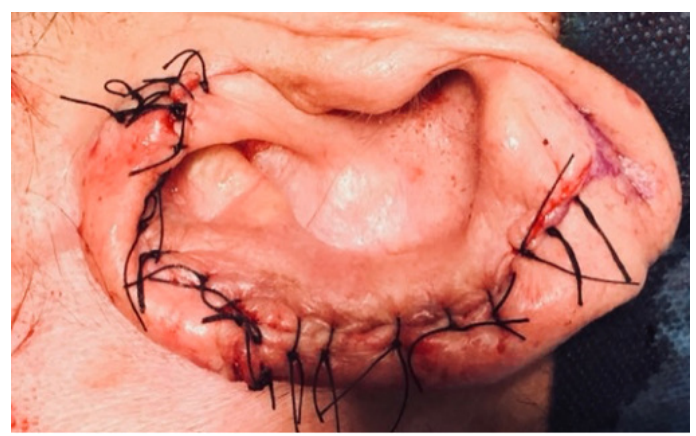

Figura 6. Cierre y reconstrucción. 


\section{COLGAJO DE ANTIA-BUCH PARA RECONSTRUCCIÓN DE DEFECTOS DEL BORDE HELICIAL. DESCRIPCIÓN DE UN CASO \\ SALOM-COVEÑAS C ET AL}

\section{DISCUSIÓN}

Se han descrito varias técnicas para la reconstrucción de los defectos del borde helicial. Los pequeños defectos se pueden cerrar tras resección en cuña. Para defectos de tamaño mediano, pueden usarse colgajos de avance condrocutáneo, colgajos de rotación o injertos compuestos contralaterales. Los defectos grandes generalmente requieren un colgajo fascial temporoparietal con injertos de piel y cartílago $[2,3]$.

La reconstrucción del pabellón, en caso de pérdida de sustancia, ya sea postraumática o posquirúrgica, plantea un problema complejo al cirujano, que debe esforzarse en restituir lo mejor posible las características de esta estructura, de forma que se obtenga una oreja de aspecto natural $[3,4]$.

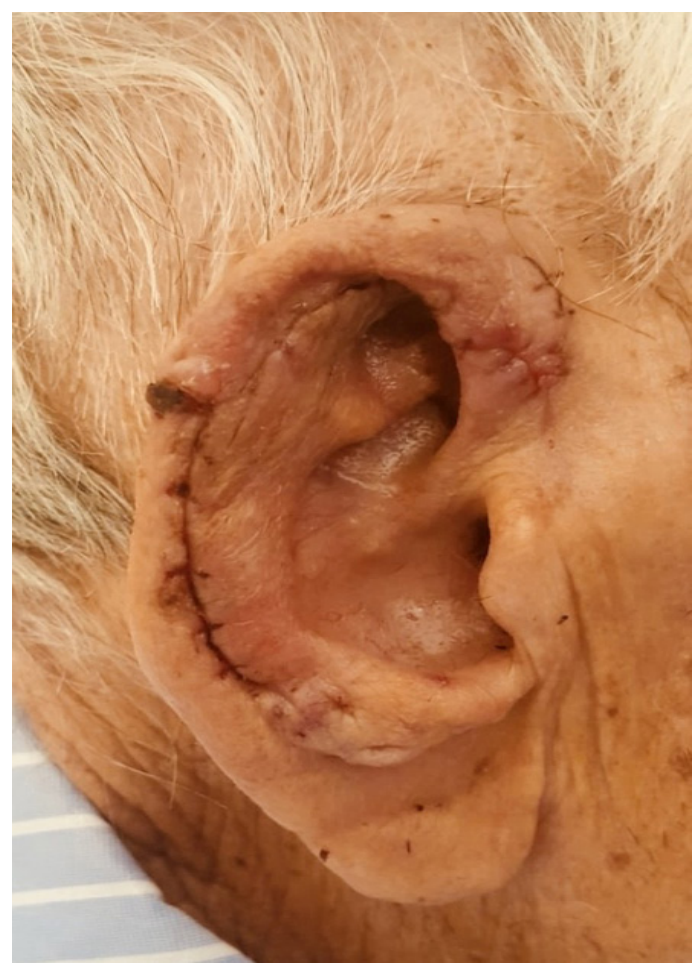

Figura 7. Resultado tras retirada de puntos.
El colgajo de Antia-Buch descrito por primera vez en 1967 [5] para defectos de mediano tamaño de la región helicial. Algunos puntos a destacar en la realización del mismo, tal como hemos descrito en nuestro caso clínico, van a ser: la realización de descargas V-Y, que se realizarán a demanda, según el defecto que quede tras la exéresis y así evitar mayor tensión de los tejidos; conservar el pericondrio del colgajo para la nutrición condral y la realización del triángulo compensatorio de Burow en la región posterior del defecto para lograr un mejor cierre sin perder la orientación del pabellón $[2,3,6]$.

\section{CONCLUSIONES}

La técnica de reconstrucción helicial mediante el colgajo de Antia-Buch es confiable con la que puede obtenerse un buen resultado estético sin comprometer la radicalidad de la excisión de tumores localizados en los tercios superior o medio del hélix.

\section{BIBLIOGRAFÍA}

1. Tay S, Nikkah D, Teo T. The Antia-Buch flap revisited. Clin.Otolaryngol.2016, 42, 951-3.

2. Morán K, Cabrera A, Cardona M, Medina A, Alcalá $\mathrm{D}$, Torres $\mathrm{S}$, et al. Técnicas de reconstrucción básicas del pabellón auricular por padecimiento dermatooncológico. Dermatol Rev Mex. 2015;59:310-6.

3. Chung S, Feintisch A, Lee E. Helical RIm Reconstruction: Antia-Buch Flap. Eplasty. 2015; 15:ic55.

4. Joshi R, Sclafani AP. The Antia-Buch chondrocutaneous advancement flap for auricular reconstruction. Ear Nose Throat J. 2016; 95(6):216-7.

5. Antia NH, Buch VI. Chondrocutaneous advancement flap for the marginal defect. Plast Reconstr Surg. 1967;39(5):472-7.

6. Dreiman BB. Chondrodermatitis nodularis chronica helicis treated with Antia-Buch reconstruction: review and case report. J Oral Maxillofac Surg. 2007 Jul;65(7):1378-82. 